\title{
Use of internal growth bands for measuring individual and population growth rates in Mytilus edulis from offshore production platforms
}

\author{
C. A. Richardson, R. Seed, E. Naylor \\ University of Wales, Bangor, School of Ocean Sciences, Menai Bridge, Gwynedd LL59 5EY, United Kingdom
}

\begin{abstract}
Age and growth rates of Mytilus edulis from the Forties Bravo oil production platform in the North Sea and the Morecambe Flame gas exploration platform in the Irish Sea were assessed using internal growth patterns in shell sections. Clear annual growth lines in the nacreous layer were used to determine the age of mussels, whilst the tidally induced microgrowth bands in the prismatic layer enabled both the age and linear growth rate of individual mussels to be established. Considerable variation in individual growth rates occurred both within and between populations. No consistent relationship was observed between population growth rate and water depth on the 2 platforms. Age estimates of individuals taken from population subsamples showed that the Morecambe Flame and Forties Bravo platforms contained 3 and 11 year classes respectively but that these did not coincide with any obvious size classes present in the populations studied. The use of internal growth bands provides a reliable method in which individual and population growth rates can be accurately determined from a single sample of the population. Their use is especially valuable in habitats such as offshore platforms or water intake pipes where conventional methods involving repeated sampling of the population are difficult or impracticable.
\end{abstract}

\section{INTRODUCTION}

The common blue mussel Mytilus edulis (L.) is widely distributed in boreal and temperate waters especially in the littoral and shallow sublittoral zones where it often forms extensive mussel-dominated communities (e.g. Lewis 1964, Seed 1976, Suchanek 1985). In colder higher latitudes, however, it is largely restricted to the sublittoral zone (Kautsky 1982). M. edulis occurs on a wide variety of substrata, including rocky surfaces, compacted mud, ships hulls, pier pilings, harbour walls and in power station water-cooling culverts. The arrival and proliferation of permanent offshore structures for oil and natural gas production in many parts of the world has provided alternative attachment sites for many forms of marine life including mussels. The submerged portions of these structures effectively enable mussels to extend their vertical distribution into much deeper water (e.g. Wolfson et al. 1979, Ralph \& Troake 1980, Fortreath et al. 1982).

On production platforms in the North Sea Mytilus edulis occurs from around mean low water level to depths of ca $30 \mathrm{~m}$ (Fortreath et al. 1982). The abundance of mussels on these structures can vary consider- ably from only a few isolated individuals to situations in which mussels are the dominant group of fouling organisms. In the Santa Barbara Channel off the coast of California, USA, Page \& Hubbard (1987) found that although mussels occurred to depths of $18 \mathrm{~m}$, they were most abundant between the surface and $10 \mathrm{~m}$.

Previous biological studies of offshore platforms have tended to concentrate principally on the structure and ecology of the total fouling community together with its associated fish populations (e.g. Carlisle et al. 1964, George \& Thomas 1979, Goodman \& Ralph 1981). Dominant fouling organisms such as mussels however present serious problems of drag and platform stability which necessitate the costly routine of cleaning these structures in an often hostile environment. Conventional methods of measuring growth in mussels have usually involved the use of surface growth rings and/or size frequency analysis of the population but both these methods have serious limitations in Mytilus edulis (for review see Seed \& Richardson 1990) and size frequency analysis, even when applicable, requires repeated sampling of the population. Clearly the ability to measure growth rates from single population samples will be especially valuable in habitats such as offshore plat- 
forms or water intake pipes where more conventional methods involving population sampling may be difficult or impracticable. In this study we investigated the use of internal growth patterns within the shell structure of $M$. edulis to estimate the age and growth rate from single samples of mussel populations from a permanent oil production platform in the North Sea and a mobile exploration platform temporarily located in the Irish Sea.

\section{MATERIALS AND METHODS}

Samples of Mytilus edulis were obtained from approximately mean low water (MLW) and depths of $25 \mathrm{~m}$ from the legs of the British Petroleum platform Forties Bravo operating in the North Sea off the northeast coast of Scotland $\left(57^{\circ} 50^{\prime} \mathrm{N}, 01^{\circ} \mathrm{O}^{\prime} \mathrm{E}\right)$ and from the legs of the British Gas exploration platform Morecambe Flame situated in Morecambe Bay off the northwest coast of England ( $53^{\circ} 51^{\prime} \mathrm{N}, 03^{\circ} 35^{\prime} \mathrm{W}$ ). Samples were collected during routine diving operations on the Forties Bravo platform on 17 August 1987 and those from the drilling rig Morecambe Flame were scraped from the raised legs on 9 September 1987 during site relocation.

Shell length (maximum anterior-posterior growth axis) of all mussels was measured to the nearest $0.1 \mathrm{~mm}$ using vernier calipers. Representative samples of 50 mussels from each of the 4 samples were then selected for more detailed analysis. The internal shell structure of each mussel in these subsamples was observed by examining acetate peel replicas of polished and etched radial shell sections of resin-embedded shell valves, using methods previously described by Lutz (1976) and Richardson (1989). The age of each mussel was determined from the prominent annual growth lines present in the nacreous layer (Lutz 1976) and the tidally induced microgrowth bands in the prismatic layer of the shell (Richardson 1989). The advantage of using the prismatic bands is that the distance between successive bands in this layer represents the actual linear increase in shell length. The lines in the nacreous layer can also be used to estimate growth rate but the relationship between the spacings of these lines and shell length would first have to be established.

In order to understand how the appearance of the tidal microgrowth bands changes seasonally, local intertidal mussels were marked and grown for 1 yr (May 1987 to May 1988) at approximately mid-tide level (MTL) in a plastic mesh cage in the Menai Strait, North Wales. This approach was necessary because we were unable to obtain permission to set up comparable experiments on the rigs themselves. During autumn, winter, spring and summer approximately 10 mussels were removed from the cage and sectioned and the appearance of the most recently formed microgrowth bands examined. These sections showed a progressive narrowing of the bands throughout the autumn and winter as growth rate slowed with declining seawater temperatures. Mussels from the rigs exhibited a comparable banding pattern to the experimental mussels, and we have assumed that this is similarly seasonrelated.

From the known length of mussels of any given age, determined both from the nacreous and prismatic lines, average growth curves could be constructed for the 4 platform populations. When constructing these population growth curves, data from a wide size range of mussels were used. Growth curves of individual mussels were obtained from measurements of the distance between the umbo and successive groups of narrow winter bands in the prismatic layer.

\section{RESULTS}

The arrangement of the different layers of the shell of Mytilus edulis is shown in Fig. 1 and 2. The shell consists of an outer horny periostracum, a middle calcitic prismatic layer and an inner nacreous layer. Tidal growth bands bisect the calcite needles at $40^{\circ}$ in the prismatic layer (Fig. 1A). The appearance of the tidal bands during the winter period of shell growth in a peel from a marked mussel grown at mean tide level (MTL) in the Menai Strait and collected in May 1988 is shown in Fig. 1A. The narrowing of the growth increments during the autumn and winter and their subsequent increase in width during the following spring is readily visible. Mussels from the oil rig and gas platform also exhibit this narrowing of growth increments associated with the reduced growth rate during winter (Fig. 1B).

Occasionally areas within the shell could be observed where the regular pattern of growth bands was suddenly interrupted, thus resulting in a number of narrowly spaced bands. These disturbance lines, which are frequently associated with a cleft in the shell section and a ring on the outer shell surface (Fig. 2A), are associated with short-term cessations of growth rather than with any longer-term (annual) seasonal effects. The precise nature of these lines was verified by comparison with rope-cultured mussels from Ballochmartin. Bay in the Clyde Estuary, Scotland, which had been subjected to regular periods of disturbance (Fig. 2B). In most peels disturbance lines could easily be distinguished from the narrow tidal bands deposited during the winter, but in a few larger, older shells, where the annual growth increments were small and the annual lines crowded together, it was not always possible to distinguish between these 2 kinds of growth lines. The 

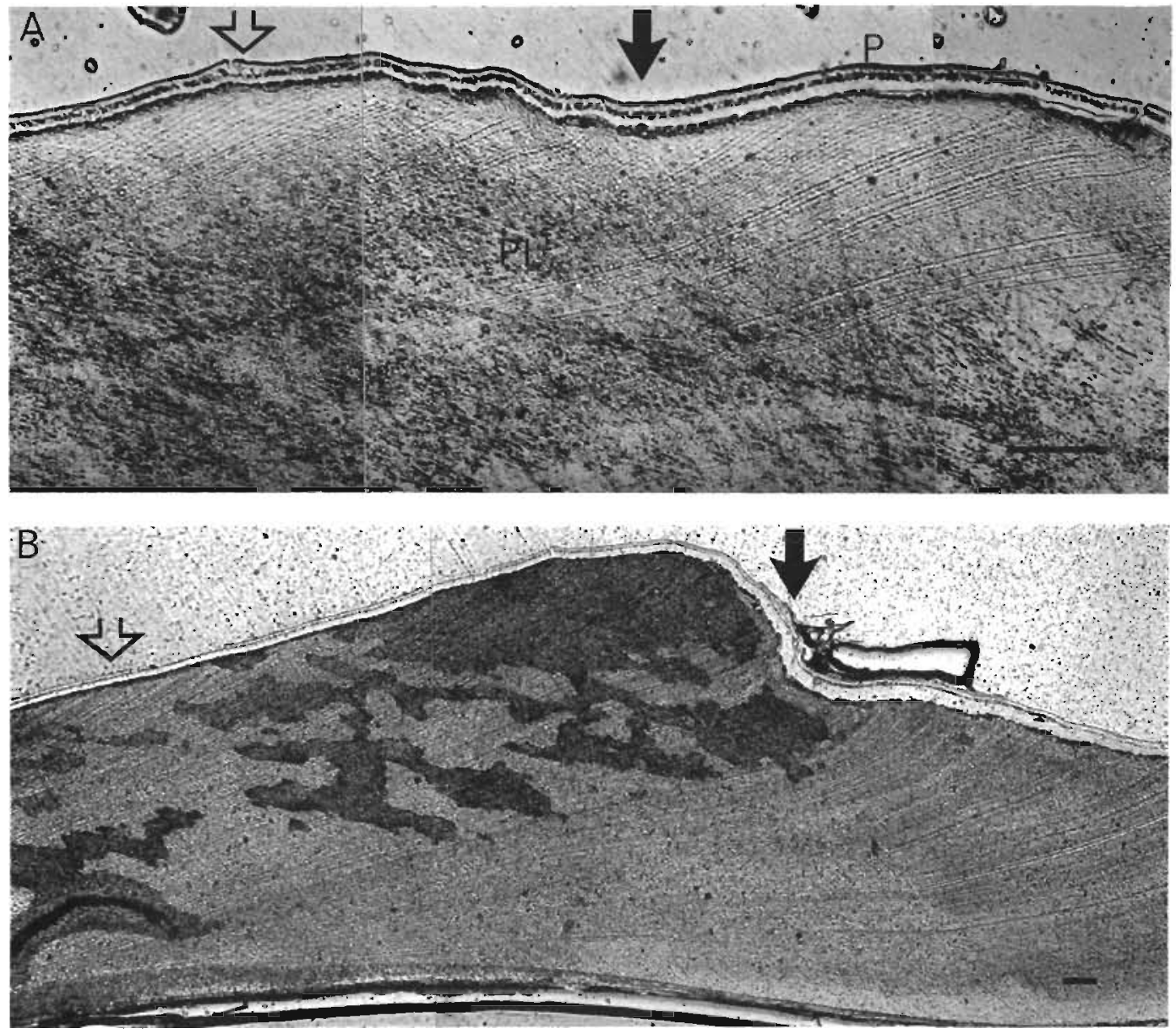

Fig. 1 Mytilus edulis. Photomicrographs of acetate peels of shell sections showing a narrowing of the growth increments in the prismatic layer (PL) during the autumn (open arrows) and narrow increments in the winter (filled arrows). (A) Mussel from mean tide level in the Menai Strait. P: periostracum. (B) Subtidal mussel from the Forties Bravo oil production platform. Scale bars $=100 \mu m$

annual periodicity of the nacreous lines in Mytilus edulis was confirmed in this study for 2 -yr-old raft-grown mussels in Ballochmartin Bay in which 2 annual lines were clearly visible. Fig. 2C, D shows the appearance of the growth lines in the nacreous layer in peels of 2- and 9-yr-old mussels respectively.

Age estimates obtained from growth lines present in the prismatic layer (Fig. 1) and those present in the nacreous layer (Fig. 2C, D) were well correlated (in all cases $r \geqslant 0.862, p<0.001$ ); these estimates either corresponded exactly, or, for a small number of the older mussels, differed by only 1 or 2 yr. Fig. 3 A to Cillustrates the absolute growth in shell length for the Morecambe Bay, Forties Bravo and combined populations respectively. No significant differences or consistent relationship between growth rate or water depth in these populations were observed. Curves for the Forties Bravo populations were fitted using the Von Bertalanffy growth equation. The maximum asymptotic size $\left(\mathrm{L}_{s 0}\right)$ and the growth constant $(\mathrm{K})$, together with the $95 \% \mathrm{CI}$, for the MLW and subtidal populations were
$75.81 \pm 5.82 \mathrm{~mm}, 0.385 \pm 0.101$, and $70.54 \pm 3.10 \mathrm{~mm}$, $0.345 \pm 0.066$, respectively. No meaningful asymptotic regression equation could be fitted to the Morecambe Bay population data in which only 4 year classes were represented. The maximum age of mussels from these 2 offshore platforms varied from $3 \mathrm{yr}$ on the Morecambe Flame to 11 yr on the Forties Bravo. Growth rates of individual mussels from the subtidal population on the North Sea platform illustrate the large variation that can exist within any mussel population (Fig. 3D). Mussel number 67, for example, attained a shell length of only $37 \mathrm{~mm}$ in $4 \mathrm{yr}$ whilst over the same period a conspecific mussel (number 13) had reached a length of $77 \mathrm{~mm}$, which is close to the asymptotic length $(86.8 \mathrm{~mm})$ of this individual.

Fig. 4 illustrates the size frequency distributions of the 4 populations together with the estimated age determined from subsamples of these populations. The low intertida]. population from the Morecambe Bay platform, although unimodal, included at least 4 separate year classes (Fig. 4A). The subtidal sample, by con- 

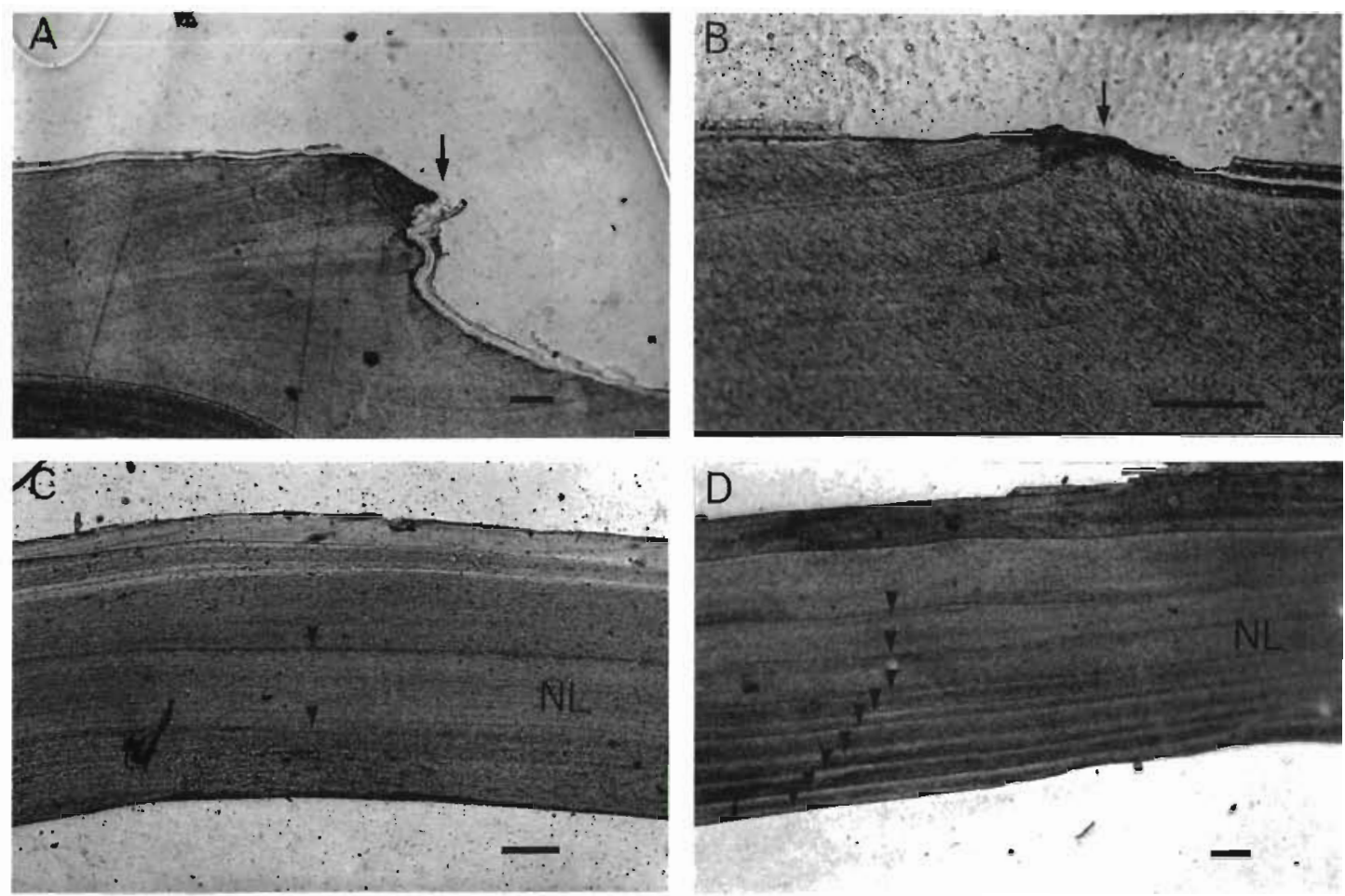

Fig. 2. Mytilus edulis. Photomicrographs of acetate peels of shell sections. (A) Subtidal mussel from the Forties Bravo platform showing a disturbance in growth (arrow). (B) Disturbance mark in a rope-cultured mussel shell in Ballochmartin Bay which had been subjected to regular periods of disturbance. (C) Two growth lines (arrows) in the nacreous layer (NL) of the shell of a subtidal mussel from the Morecambe Flame gas platform, and (D) 9 growth lines in the nacreous layer of the shell of a subtidal mussel from the Forties Bravo platform. Scale bars $=200 \mu \mathrm{m}$

trast, is essentially bimodal (Fig. 4C) and whilst the group of smaller mussels possibly represents newly recruited individuals the mode of larger mussels does not appear to correspond to any single year class within this particular population. Mussels on the Forties platform achieved an overall greater shell length and included substantially more year classes than the populations from the Morecambe Bay platform. The subtidal population was again essentially bimodal (Fig. 4D) with a smaller mode of newly recruited mussels and a larger mode of much older (5 to $11 \mathrm{yr}$ ) individuals. Mussels aged 1 to $4 \mathrm{yr}$, on the other hand, appear to be relatively under-represented in this population. No obvious modes are evident in the population from the low intertidal population which consisted mainly of young mussels less than 5 yr old (Fig. 4B).

\section{DISCUSSION}

Size frequency distributions for some species of bivalves are distinctly polymodal with each mode representing an individual year class. By estimating the mean size of these modes population growth rate can be assessed. This, however, is usually possible only for those species in which the period of recruitment is relatively restricted and where growth rates of individuals within each year class are fairly uniform (Cerrato 1980 ). Where annual recruitment is more extended and individual growth rates more variable, as in many Mytilus edulis populations, size frequency distributions are of limited value in estimating population growth rate (Seed 1976, Kautsky 1982). In the mussel populations studied during this investigation the only size class which corresponded to a particular age class was that comprising first year individuals and even this was discernible only in the subtidal populations. All subsequent year classes were impossible to separate due to the variability in individual growth rates which results in the faster growing mussels from one year class overlapping the slower growing mussels from previous year classes. Thus whilst analyses of size frequency distributions have previously been used to estimate growth rates of $M$. edulis elsewhere (e.g. Thiesen 1968, Bayne \& Worrall 1980, Rodhouse et al. 1984) they are clearly of little or no value for estimating the age and growth rates of mussels studied in this investigation

Surface rings, resulting from seasonal changes in shell growth, have previously been used with varying degrees of success to determine the age of Mytilus edulis (see Seed \& Richardson 1990 for review). In the present study surface rings were often indistinct and 

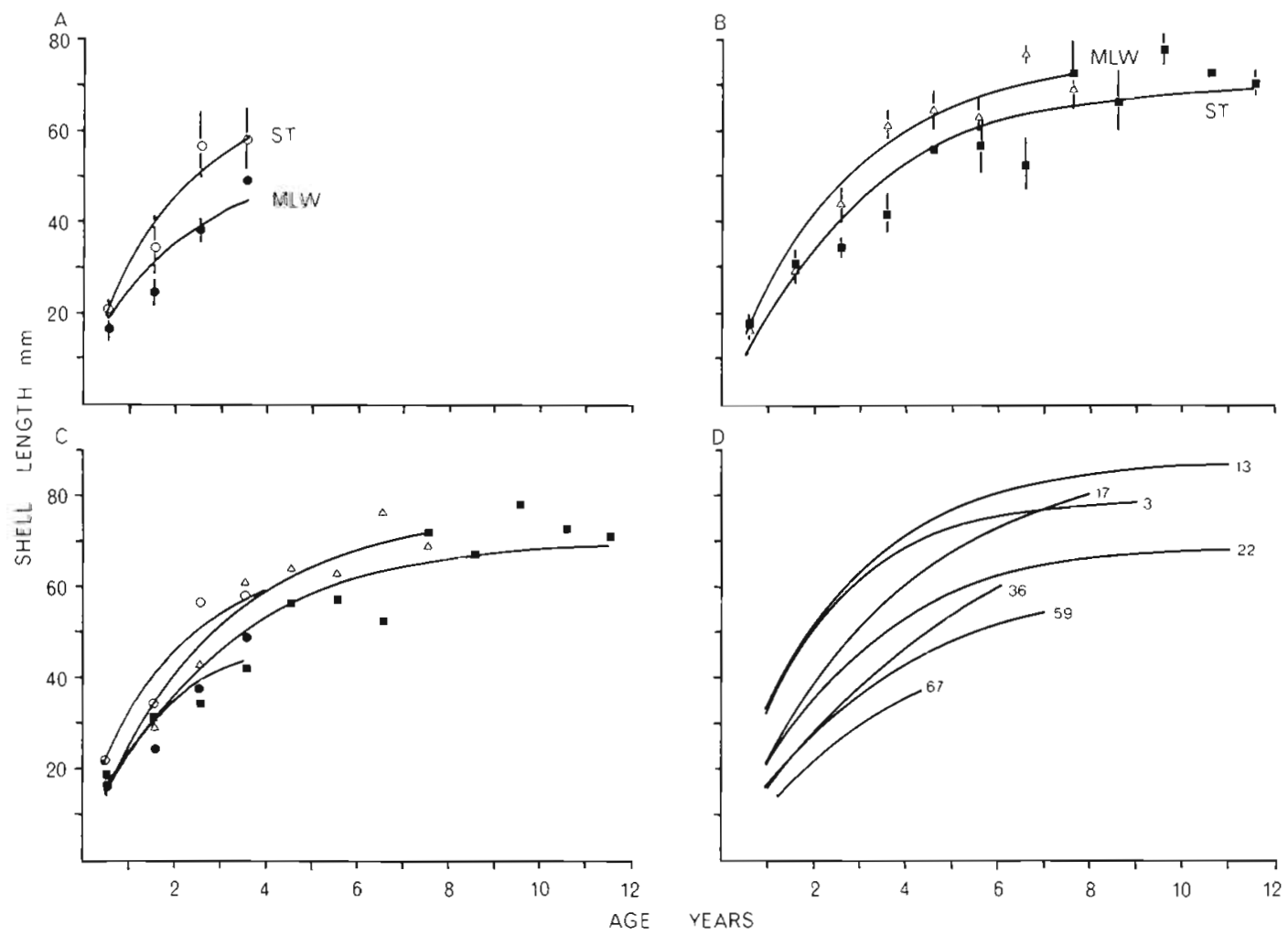

Fig. 3. Mytilus edulis. Absolute growth in shell length as determined from growth increments in the prismatic layer for the platform mussel populations. (A) Morecambe Bay. MLW - mean low water; ST: subtidal. (B) Forties Bravo. Von Bertalanffy growth curves fitted. (C) Comparison of the 4 populations. (D) Growth of numbered individuals from the subtidal population on the Forties Bravo platform. Von Bertalanffy growth curves fitted

therefore unreliable indicators of age, particularly in the Morecambe Bay populations. Annual growth lines in the nacreous layer of the shell, by contrast, provide an alternative method for determining the age and growth rate of $M$. edulis (see e.g. Lutz 1976, Bayne \& Worrall 1980, Rodhouse et al. 1984) and these have been used successfully in this investigation. Although this technique allows the age of individual mussels and therefore population growth rate to be assessed it does not enable the linear growth rates of individual mussels to be determined unless the relationship between growth of the nacreous layer lines and shell length is first established. In this study sections of individual mussel shells grown in plastic mesh cages at MTL in the Menai Strait and sampled throughout the year have shown that the tidal microgrowth patterns present in the outer prismatic layer also reveal clearly marked annual patterns of deposition. The identification of these patterns, which result from the narrowing of the tidal growth bands during the colder winter months,

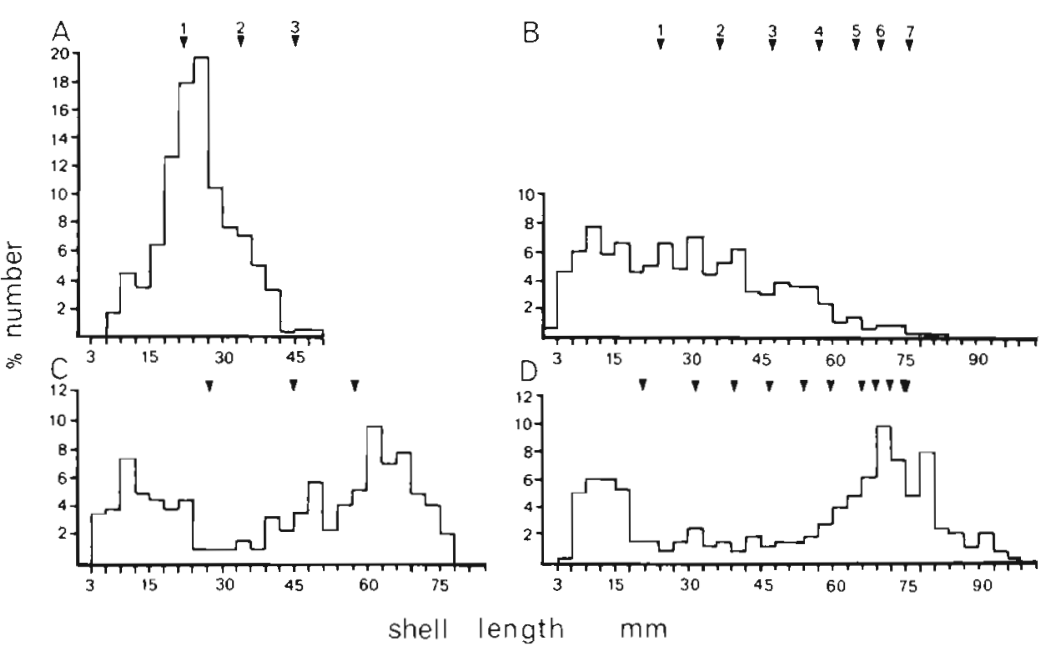

Fig. 4. Mytilus edulis. Size frequency distributions of the 4 populations together with estimated age in years (arrows) determined from the subsamples of these populations. (A, C) Morecambe Bay $(n=500,386$ respectively); $(B$, D) Forties Bravo populations ( $\mathrm{n}=500,323$ respectively). (A, B) Low intertidal, (C, D) subtidal populations 
has for the first time permitted the past growth history of individual mussels to be determined.

The first oil field to be discovered in the North Sea was the Montrose Field and a steel production platform was installed there in August 1975 (Fortreath et al. 1982). The 'Forties Bravo' platform in the Forties Field lies some $40 \mathrm{~km}$ northwest of the Montrose Field and was commissioned in 1976. Using the internal growth lines in shell sections the oldest mussels from the 'Forties Bravo' platform recorded during this investigation were $11 \mathrm{yr}$ old; this coincides exactly with the known age of this platform at the time these samples were collected. Although the mussels in the 'Morecambe Flame' samples were estimated to be only 3 yr old these too corresponded exactly to the known age of this rig. These observations thus confirm that the internal nacreous lines and the groups of narrow winter bands in the prismatic layer within these offshore mussel populations have an annual periodicity.

One of the most striking features of growth in Mytilus edulis which has been clearly demonstrated in this study is the degree to which it varies amongst individual mussels from the same age groups within each population. Thus, whilst some individuals attained shell lengths of $70 \mathrm{~mm}$ in their first few years of growth. others within the same population attained shell lengths of 25 to $30 \mathrm{~mm}$ during the same period. Such reductions in growth rate may reflect intense intraspecific competition. In populations containing several age classes large numbers of small mussels may become ensnared amongst the byssal threads of larger individuals and are consequently at a severe disadvantage in their competition for food (Seed 1969, Kautsky 1982).

Growth of Mytilus edulis can be modulated by several interacting factors including water temperature and depth, food availability and the degree of aerial exposure (reviewed by Seed \& Richardson 1990). On an offshore oil platform in the Santa Barbara Channel, California, Page \& Hubbard (1987) found no obvious correlation between growth and water temperature but a significant correlation with food availability, measured as chlorophyll a concentration. Growth rates were highest at a depth of $9 \mathrm{~m}$ although variations in growth rate with depth were more closely associated with particulate carbon than with chlorophyll a. There was no significant differences between the growth rates of mussels located at 2 or $18 \mathrm{~m}$. A major difficulty in correlating growth rate with environmental factors is that many of these factors co-vary; consequently, although a correlation may be apparent, the relationship may not necessarily be causal. In the present study there was no consistent or significant relationship between growth rate and water depth on the 2 platforms.

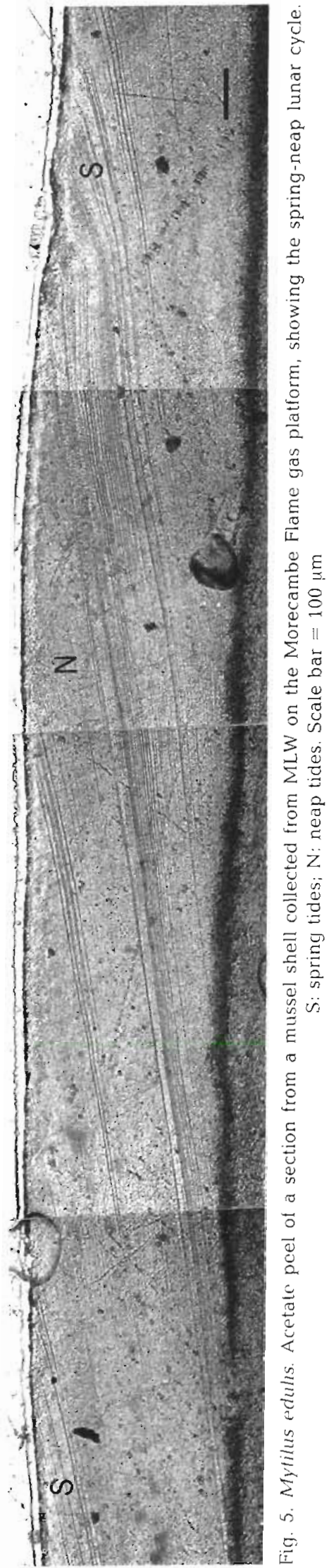


A tidally induced banding pattern with a ca $14 \mathrm{~d}$ periodicity has previously been demonstrated within the prismatic shell of Mytilus edulis at mean low water in the Menai Strait (Richardson 1989). A similar banding pattern is also evident in mussels from the low intertidal populations on the 2 offshore platforms. These patterns are related to the spring-neap lunar cycle. During spring tides, when mussels are emersed twice a day, a pattern of strongly defined bands is produced, whilst during neap tides, when the mussels remain continuously immersed, weakly defined bands are produced (Fig. 5). Measurement of the distance between groups of strongly and weakly defined bands therefore provides an estimate of the fortnightly fluctuations in shell growth $\left(0.3\right.$ to $\left.2.0 \mathrm{~mm} 14 \mathrm{~d}^{-1}\right)$. Moreover, by measuring the width of the most recently deposited bands at the growing margin of the shell, the effects of environmental factors on daily or even tidal growth rates $\left(0.05\right.$ to $\left.0.1 \mathrm{~mm} \mathrm{~d}^{-1}\right)$ could be assessed. The use of tidally produced microgrowth bands is especially valuable for determining the age of intertidal mussels when no obvious seasonal growth patterns can be observed in the shell. In such cases the number of bands can be counted within a $1.0 \mathrm{~mm}$ unit length of shell at several locations along the section. These values are then plotted against distance along the shell and a suitable polynomial equation fitted to the data. Solving the integrated expression provides an estimate of the total number of tidal bands present within the shell. This method has recently been used to estimate the age of the Malaysian cockle Anadara granosa (Richardson 1987 ) and could equally well be used to determine the age of $M$. edulis where seasonal banding patterns may be absent.

In subtidal mussels the tidally induced banding pattern is not apparent. However, patterns of weak growth bands resulting from an endogenous rhythm of shell deposition with no apparent environmental periodicity (Richardson 1989) have been observed in the prismatic layer of Mytilus edulis. Similar weak growth bands were also observed in the prismatic layer of subtidal mussels from the platforms and these too would be of little or no value in measuring short-term variations in shell growth.

Acknowledgements. We are grateful to Dr J. P. Hartley (BP Exploration Ltd., Aberdeen) and Mr D. Crellin (British Gas plc, London) who kindly provided the samples of mussels from the 'Forties Bravo' and 'Morecambe Flame' platforms repectively. Mr D. Chevis (University Marine Biological Station Millport) kindly supplied a sample of mussels from rope culture in Ballochmartin Bay in the Clyde Estuary. We thank the SERC Marine Technology Directorate for financial support.

\section{LITERATURE CITED}

Bayne, B. L., Worrall, C. M. (1980). Growth and production of mussels Mytilus edulis from two populations. Mar Ecol. Prog. Ser 3: 317-328

Carlisle, J. G. Jr., Turner, C. H., Ebert, E. E. (1964). Artificial habitat in the marine environment. Bull. Dep. Fish. Game St. Calif. 124: 1-93

Cerrato, R. M. (1980). Demographic analysis of bivalve populations. In: Rhoads D. C., Lutz, R. A. (eds.) Skeletal growth of aquatic organisms. Plenum Press, New York, p. 417-468

Fortreath, G. N. R., Picken, G. B., Ralph, R., Williams, J. (1982). Marine growth studies on the North Sea oil platform Montrose Alpha. Mar Ecol. Prog. Ser 8: 61-68

George, R. Y., Thomas, P. J. (1979). Biofouling community dynamics in Louisiana shelf oil platforms in the Gulf of Mexico. Rice University Studies 65 (4 \& 5): 553-574

Goodman, K. S., Ralph, R. (1981). Animal fouling on the Forties platforms. In: Marine fouling of offshore structures. Society of Underwater Technology, London, 19-20 May

Kautsky, N. (1982). Growth and size structure in a Baltic Mytilus edulis population. Mar Biol. 68: 117-133

Lewis, J. R. (1964). The ecology of rocky shores. English Universities Press, London

Lutz, R. A (1976). Annual growth layers in the shell of Mytilus edulis. J. mar. biol. Ass. U.K. 56: 723-731

Page, H. M., Hubbard, D. M. (1987). Temporal and spatial patterns of growth in mussels Mytilus edulis on an offshore platform: relationships to water temperature and food availability. J. exp. mar. Biol. Ecol. 111. 159-179

Ralph, R., Troake, R. P. (1980). Marine growth on North Sea platforms. 12th Annual Offshore Technology Conference, Houston, Texas, Vol 4, p. 49-51

Richardson, C. A. (1987). Microgrowth patterns in the shell of the Malaysian cockle Anadara granosa (L.) and their use in age determination. J. exp. Mar Biol. Ecol. 111 77-98

Richardson, C. A. (1989). An analysis of the microgrowth bands in the shell of the common mussel Mytilus edulis. J. mar biol. Ass. U.K. 69: 477-491

Rodhouse, P. G., Roden, C. M., Burnell, G. M., Hensey, M. P., McMahon, T., Ottway, B., Ryan, T H. (1984). Food resource, gametogenesis and growth of Mytilus edulis on the shore and in suspended culture: Killary Harbour, Ireland. J. mar. biol. Ass. U.K. 64: 513-529

Seed, R. (1969). The ecology of Mytilus edulis L. (Lamellibranchiata) on exposed rocky shores. 2. Growth and mortality. Oecologia (Berl.) 3: 317-350

Seed, R. (1976). Ecology, In. Bayne, B. L. (ed.) Marine mussels: their ecology and physiology, Cambridge University Press, Cambridge, p. 13-65

Seed, R., Richardson, C. A. (1990). Mytilus growth and its environmental responsiveness. In: Stefano. G. B. (ed.) The neurobiology of Mytilus edulis. Manchester University Press, Manchester, p. 1-137

Suchanek, T. H. (1985). Mussels and their role in structuring rocky shore communities. In: Moore P. G., Seed, R. (eds.) The ecology of rocky coasts. Hodder \& Stoughton, Sevenoaks, p. 70-96.

Thiesen, B. F. (1968). Growth and mortality of culture mussels in the Dannish Wadden Sea. Meddr Danm. Fisk.-og Havunders. N.S. 6: 47-78

Wolfson, A., Van Blaricom, G., Davis, N., Lewbel, G. S. (1979). The marine life of an offshore platform. Mar. Ecol. Prog. Ser 1: 81-89

Manuscript first received: April 12, 1990

Revised version accepted: July 11, 1990 